\title{
The movement ecology of the Mauritian flying fox (Pteropus niger): a long-term study using solar-powered GSM/GPS tags
}

Ryszard Z. Oleksy ${ }^{1,2,3,5}$, Charles L. Ayady ${ }^{3,5}$, Vikash Tatayah ${ }^{5}$, Carl Jones ${ }^{4,5}$, Paul W. Howey ${ }^{6}$, Jérémy S. P. Froidevaux ${ }^{1}$, Paul A. Racey ${ }^{7}$ and Gareth Jones ${ }^{1 *}$ (D)

\begin{abstract}
Background: Flying foxes (Chiroptera: Pteropodidae) are large bats that often roost in the sun, hence solar-powered GPS/GSM devices can track their movements over extended periods. The endemic Mauritian flying fox (Pteropus niger) has recently been subjected to large-scale culling because of perceived damage to commercial fruit, and a consequent reduction in numbers of $>50 \%$ since 2015 resulted in its IUCN Red List Status being up-listed to Endangered. Determining its movements will be important for management and conservation, for understanding potential responses to environmental change, and for understanding population admixture.

Methods: Twelve bats were tagged with solar-powered GPS/GSM devices in 2014-2016. Tags remained active for up to almost a year (maximum 359 days: average 139 days (males) and 93 days (females)), providing some of the longest-term data on the movement ecology of bats yet obtained. Eight bats were probably hunted illegally, highlighting the scale of unauthorised persecution.

Results: Males travelled on average $9 \mathrm{~km}$ each night, females $6 \mathrm{~km}$. The nightly distance covered by adults of both sexes was higher in winter than in summer, though the opposite pattern occurred for immature males. These differences are probably related to seasonal changes in fruit availability (adults) and to dispersal by immature males. The maximum distance covered during one night was $>92 \mathrm{~km}$. Home ranges of males averaged 74,633 ha, females $31,072 \mathrm{ha}$. Core foraging areas averaged 2222 ha for males, 1364 ha for females. Fifty roosts were identified, mainly in forest fragments. As the bats disperse seeds of native plants that form forest canopies, conservation of the bats will potentially maintain and enhance native forest cover, in turn providing roosting sites for the bats.

Conclusions: Solar-powered GSM tagging provides unprecedented potential for understanding the movement ecology of flying foxes. Mauritian flying foxes often move between the few remnant native forest fragments, which remain important for their conservation, and have potentially important roles in seed dispersal. Their nomadic movement fits with their panmictic genetic structure. Although their ability for long distance movements, sometimes over short timescales, permits rapid responses to local threats and environmental change, being restricted to Mauritius renders the bats extremely vulnerable to intense culling.
\end{abstract}

\footnotetext{
* Correspondence: gareth.jones@bristol.ac.uk

${ }^{1}$ School of Biological Sciences, Life Sciences Building, University of Bristol, 24

Tyndall Avenue, Bristol BS8 1TQ, UK

Full list of author information is available at the end of the article
}

C The Author(s). 2019 Open Access This article is distributed under the terms of the Creative Commons Attribution 4.0 International License (http://creativecommons.org/licenses/by/4.0/), which permits unrestricted use, distribution, and reproduction in any medium, provided you give appropriate credit to the original author(s) and the source, provide a link to the Creative Commons license, and indicate if changes were made. The Creative Commons Public Domain Dedication waiver (http://creativecommons.org/publicdomain/zero/1.0/) applies to the data made available in this article, unless otherwise stated. 


\section{Background}

Movement of individual organisms is one of the most fundamental features of life on earth and a major component of ecological and evolutionary processes [1]. Animals move for many reasons such as the search for resources, predator or competition avoidance and to be near conspecifics for mating and other social interactions [2]. Movement plays a pivotal role in shaping biodiversity patterns across spatiotemporal scales. It affects biodiversity directly and indirectly by determining how species are distributed and how they interact [3, 4]. Movement patterns can also help understand how animals may respond to threats and environmental change [5], and provide a framework for understanding population genetic structure [6], with unrestricted movement potentially giving rise to a lack of genetic structure, leading to panmixia over large spatial scales.

The most common types of movements involve foraging, dispersal and migration $[7,8]$, generally with major differences in spatiotemporal scales [8]. Foraging is usually undertaken within a home range, while dispersal refers to movements away from the place of birth towards another location for reproduction [8]. Migratory movements often follow seasonal fluctuations in resource availability, and can cover thousands of kilometres [8, 9]. However, spatial and temporal variability in environmental conditions may affect all types of movement across all scales, from local to global, creating new opportunities for the evolution of movement parameters $[2,10]$. Whether or not a species' movement parameters are adaptive in the changing landscape will depend on the rate of landscape change relative to the rate at which the species can evolve in response to that change [2]. The ability to move rapidly away from unsuitable conditions, or from threats can potentially have considerable adaptive value.

Understanding the movement ecology of frugivores is important given their ability to disperse seeds, often over long distances. Forested habitats are often fragmented as a consequence of deforestation, and seed dispersers play important roles in dispersing seeds among forest fragments [11]. Seed dispersal and pollination are the most threatened processes involving plant regeneration, and are recommended as priorities in the conservation of forests on a global scale [12]. Flying foxes are especially important long-distance seed dispersers in tropical and subtropical forested landscapes [13-15], and can also enhance the germination success of seeds that pass through their digestive tracts - they are potentially important for promoting forest regeneration [14].

The Mauritian flying fox (Pteropus niger) is a medium-sized frugivorous bat endemic to the Mascarene Islands. It was once distributed throughout the archipelago, although it is now restricted to the island of Mauritius (with records of several individuals present on nearby Réunion island) as a result of habitat destruction and hunting [16-19]. The species has a disproportionately large role as a seed disperser in Mauritius. It disperses the seeds of most of the woody plants in the native remnant forests on the island. Pteropus niger disperses the seeds of many endemic plant taxa, and the seeds of tall tree species that fill functionally important roles in forest canopies [20]. Pteropus niger is therefore playing a key role in ecosystem services in Mauritius, which forms part of a biodiversity hotspot [21].

Studies of the ecology and conservation status of the species were prioritised in an IUCN action plan [22], and important studies have been conducted on diet [20,23]. The island habitat limits its range and the species is significantly affected by tropical cyclones, which can decimate island populations of flying foxes [9, 24, 25]. In common with many bat species, $P$. niger produces only a single offspring per year (rarely two) so recovery after a population crash is slow [26].

In 2013, the IUCN down-listed the species from Endangered to Vulnerable due mainly to earlier increases in numbers [26]. In response to pressure from fruit growers, the Government of Mauritius authorised a national cull of over 30,000 individuals in 2015 and an additional 10,000 in late 2016 due to the damage they are perceived to cause to mango (Mangifera indica) and litchi (Litchi chinensis) fruit [26, 27]. A recent study confirmed that fruit loss due to consumption by $P$. niger can be considerable (about a quarter of all fruits monitored overall, with birds damaging a further $6 \%$ of monitored fruits [28]), although such damage can be reduced greatly by covering trees with netting [28]. In 2016 the population of $P$. niger on Mauritius was estimated at only $62,500 \pm 7 \%$, (a decline of 50\% since 2015) and given the mass culling, on-going illegal hunting, habitat degradation by invasive species and vulnerability to cyclones, the IUCN up-listed the species to Endangered once again [26]. Despite this up-listing, a further cull was initiated in 2018.

In this paper we present the first study of the movement of a fruit bat using transmitters equipped with a Global Positioning System (GPS) using the Global System for Mobile Communications (GSM). The tags were solar powered, and because the bats roost on trees in the open, could potentially transmit data over long time periods, though with a limited number of fixes per night. Because spatial data were transmitted to mobile phone networks, it was not necessary to recapture bats to download GPS fixes. Previously several studies have used GSM technology successfully on birds [29].

Little is known about the movement pattern of these bats apart from inferences that can be made from a genetic study, which concluded that the Mauritian population of $P$. niger is likely to be panmictic, with moderate to high levels of gene flow occurring among colonies distributed across the island [19]. Despite the high rate 
of deforestation of Mauritius and the highly altered and fragmented landscape with extensive plantations of sugar cane and commercial fruit, and increased levels of urban development [17], the bats survive in relatively large numbers. We tested the hypothesis that bats are 'nomadic' and able to move across the island within one night. We hypothesised that the bats' panmictic genetic structure may be a consequence of long-distance movements over the island, resulting in a lack of population differentiation. We tested whether movement patterns varied according to sex, age and season. The mating season begins around May, with females giving birth at colonies between August and December when commercial crops such as lychees and mango are fruiting in orchards and gardens [26]. We also aimed to relate movement patterns to the species' ability to respond to rapid environmental change and threats.

\section{Methods}

The study took place between December 2014 and October 2016. The bats were captured at different locations around the island (Tab. 1) using mist nets $(60 \times 60$ $\mathrm{mm}$ mesh; Ecotone, Poland) placed in tree canopies. No bats were captured close to known roosts or close to fruiting orchards. Seven out of 12 bats were tagged outside of the commercial fruiting season. Only two bats were captured in areas where fruiting orchards were nearby, at the end of the litchi fruiting season. Following capture, bats were weighed (Salter Spring Balance Scale (FKA Brands, Tonbridge, UK): capacity $2 \mathrm{~kg}$, accuracy $10 \mathrm{~g}$ ) and their forearm lengths were measured to the nearest $0.5 \mathrm{~cm}$ using a measuring tape. The bats weighed $550-800 \mathrm{~g}$ (Table 1 ), so the tags were always $<5.5 \%$ of the bats' body mass. The reproductive status of males was assessed from external examination of scrotal testes [30]. Female reproductive status was determined by examination of nipples. Small nipples with no evidence of previous suckling meant that females were nulliparous and immature [31]. Suckling resulted in the nipples becoming dark keratinised protuberances, indicative of adulthood and sexual maturity [30].

Bats were tagged with GPS/GSM devices (ca. 30 g) equipped with miniature solar panels (Microwave Telemetry, Columbia, MA, USA). The tags were attached using leather collars around the neck (with finger-wide space to ensure it was not too tight) and secured with a small bolt and a nut. The leather exposed to changing temperatures and humidity would eventually degrade and fall off, as happened with five tags. The transmitter was positioned between the shoulders of the bat. Prior to the study, the tag attachment method was tested on a captive population of Mauritius fruit bats for a period of two weeks. The tags did not affect behaviour in any obvious way and thus were considered safe to use. The tags stayed on bats for less than a month to almost a year (Table 1). Two tagged bats were observed roosting and no sign of discomfort was noticed. The data were transmitted every morning directly to Microwave Telemetry by email using GSM services (Emtel Ltd., Ebene, Mauritius) and then circulated by email to the research team. The fixes were collected at different rates depending on the battery charge, which in turn depended on the amount of solar radiation (see Results for fix return rates).

The tracks of bats were viewed using Google Earth (Google, Mountain View, CA, USA) and ArcMAP 10 (Esri, Redlands CA, USA) software. We constructed minimum convex polygons (MCPs) to determine home ranges of individual bats. MCPs contain commuting routes used by bats to reach foraging areas and to return to the roost. To better define foraging areas, we analysed utilisation distribution discontinuities, plotting the MCP area against percentage inclusion of fixes [32]. Outlying fixes can then be excluded [33, 34] and cluster cores can be used to better indicate where animals concentrate their foraging time. The method is appropriate for animals such as bats that focus foraging activities in relatively small areas, and which move rapidly between foraging sites [35, 36]. Home range analyses were performed using Ranges 7 (Anatrack Ltd., Dorset, UK [37]).

All statistical analyses were conducted using $\mathrm{R}$ v3.4.1 [38]. We tested whether nightly movement of $P$. niger differs between sex (male vs. female), age (sexually mature vs. immature), and season (summer (October-March) vs. winter (April-September)) by fitting a series of generalised linear mixed models (GLMMs, function glmer in "lme4" package [39] with negative binomial distributions to handle overdispersion. Data were beforehand rounded to the nearest integer for use in GLMMs. The interactions between sex, age, and season were incorporated as fixed effects into the models while bat ID was included as random effect to account for pseudo-replication. Model fit was verified and validated using the "DHARMa" package [40]. We then conducted model selection using the dredge function ("MuMIn" package [41]) to identify the most parsimonious model. All possible combinations of variables within the full model were ranked using the second order Akaike information criterion (AICC [42]). The model that included the three-way interaction between sex, age, and season was identified as the most parsimonious one $(\triangle A I C c$ of second best model $>4)$. We finally used the "Ismeans" package [43] to undertake post hoc contrast tests while correcting for multiple comparisons using the Tukey method.

\section{Results \\ Tagged bats}

In total 12 bats (six males and six females) were tagged with GPS/GSM transmitters (Table 1). Females that were 


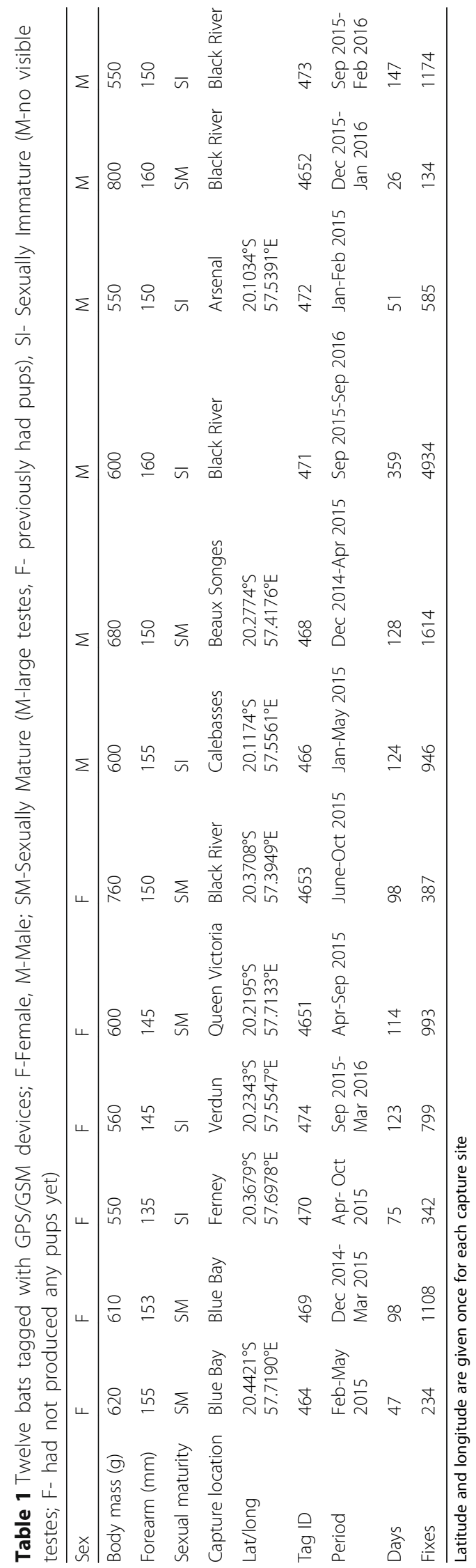


obviously pregnant, or could have dependant young, were not tagged. The average body mass of females was 617 ( $\pm 76 \mathrm{SD}) \mathrm{g}$ and of males $630( \pm 96) \mathrm{g}$. A total of 9387 fixes was collected over 835 days for males and 3863 fixes over 555 days for females. The tags remained on male bats for an average of 139 ( \pm 118 SD) days and for 93 ( $\pm 28 \mathrm{SD})$ days on females. The male monitored for the longest time provided data for 359 days, and for females maximum monitoring time was 123 days. On average the tags provided $10( \pm 3 \mathrm{SD})$ fixes per $24 \mathrm{~h}$ for males and 7 ( $\pm 3 \mathrm{SD}$ ) fixes per $24 \mathrm{~h}$ for females.

Data transmission stopped once the tag dropped off and had no access to sunlight, or when the bat was presumed killed by local people (which happened on five occasions). On two of the five occasions the tag was retrieved and re-used after a bat was killed and the tag discarded in an open field. Fortunately, these two tags had access to sunlight and kept transmitting their position, which enabled us to find them. On three occasions data transmission ended suddenly during early evening while bats was feeding on a commercial fruiting tree. The bats were probably killed and the tag destroyed or thrown away with no access to sunlight. Hence eight of 12 bats disappeared in conditions that suggested they were hunted. The rest of the tags stopped transmitting in remote forested areas.
The sites were visited based on the last GPS coordinate received but we were unable to locate the tags because of inaccessible terrain. On these occasions the tag may have remained attached, but failed to transmit data.

\section{Tracking results}

Females travelled on average $6.06( \pm 4.04 \mathrm{SD}) \mathrm{km}$ per night while males travelled 9.38 ( $\pm 5.16 \mathrm{SD}$ ) $\mathrm{km}$ per night. The longest distance travelled within one night by a male bat was $92.92 \mathrm{~km}$ in March and for a female bat $79.19 \mathrm{~km}$ in April. On a monthly basis, females travelled an average of $140.43( \pm 90.1 \mathrm{SD}) \mathrm{km}$ and males 253.84 $( \pm 164 \mathrm{SD}) \mathrm{km}$. Average nightly distances travelled by each bat varied from over $20 \mathrm{~km}$ to $<5 \mathrm{~km}$ a night.

When investigating the effects of sex, age, and season on nightly movement of $P$. niger, the most parsimonious model (Additional file 1: Table S1) included interactions among all parameters. Post hoc contrast tests (Additional file 1: Table S2) revealed that adults of both sexes move significantly greater distances during winter than in summer while nightly movement of immature males were greater in summer than in winter (Fig. 1).

The movement pattern of females and especially males (Fig. 2) is concentrated in four main forested areas: the Moka mountain range in the northwest, Bras d'Eau

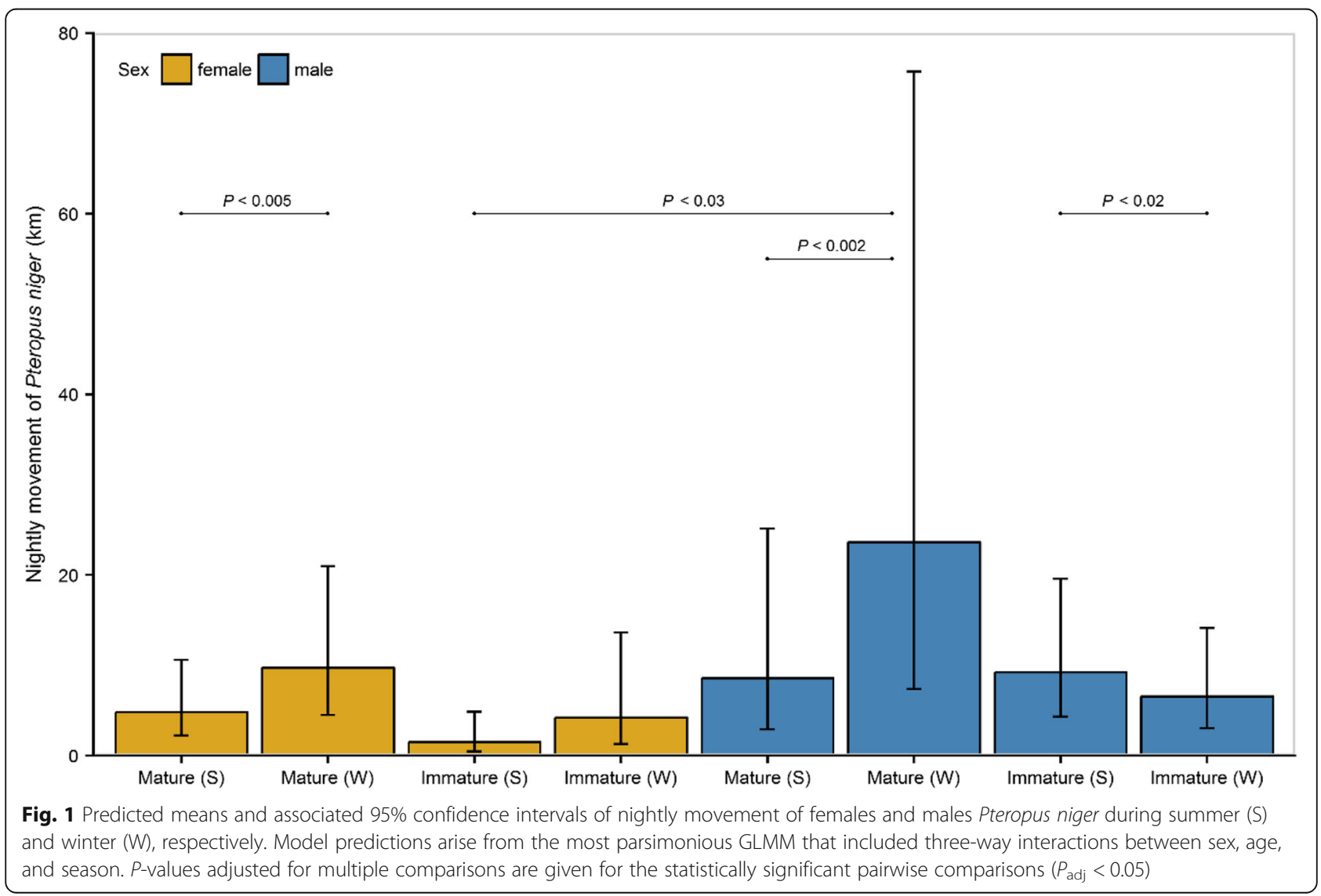




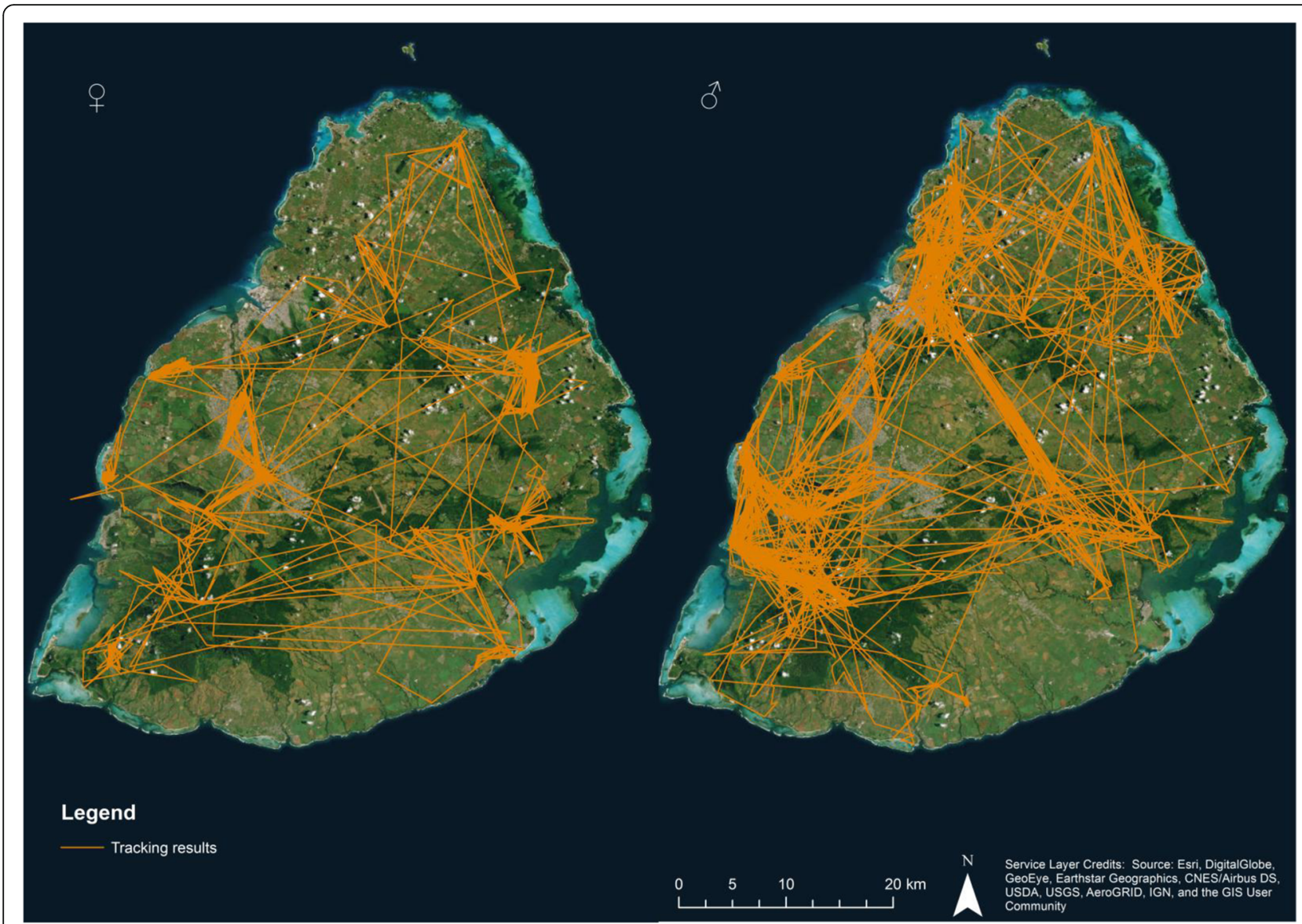

Fig. 2 Visualised tracking results (orange lines) for all tagged females (left) $(N=6)$ and males (right) $(N=6)$ over the whole period of the study (December 2014-September 2016). The main forested areas are shown in dark green

National Park in the northeast, Black River Gorges National Park in the southwest and the Bambou mountain range in the southeast. These areas host the major bat roosts in Mauritius. Our visits in the north and southwest areas during May-April and October-November to the roosting sites showed large fluctuations in bat numbers. For example the roost in Pamplemousses Botanical Garden in the north varied from over 3000 individuals in early November to around a 100 in April/May. A major roost in the Black River Gorges National Park in the southwest contained over 3000 bats in April while in November only around 300 bats were seen. We were not able to monitor roosts in the southeast due to access difficulties. However differences in movement patterns occurred between summer (October-March) and winter (April-September). In general the seasonal changes in areas occupied were more evident in males than in females (Fig. 3). The males spent more time in the south of the island during the winter and dispersed over northwest parts in the summer.

\section{Home ranges}

The home ranges for each bat (Fig. 4) varied between 1243 ha to 149,924 ha for males with a mean of 74,633 ha ( $\pm 57,302 \mathrm{SD})$; and from 1500 ha to 72,511 ha for females (mean 31,072 ha \pm 27,374 SD). An independent samples T-test showed that there is no significant difference between male and female home range size $(\mathrm{t}=$ 1.68; $\mathrm{df}=10 ; p=0.054)$, although the difference was very close to significance. The trend could be due in part to males being tagged for longer periods on average than females.

From all the roosting data (fixes collected between $07.00 \mathrm{~h}$ and $16.00 \mathrm{~h}$ ) $50 \%$ cluster core polygons were extracted to remove single fix locations and outlying fixes. That resulted in over 50 roosting sites used by $P$. niger during the whole study (Fig. 5). Roost overlap among individuals was small with an average of $12.3 \%( \pm 10.47$ SD) overlap among all of the tracked individuals over the duration of the study, meaning that tagged bats rarely roosted together. 


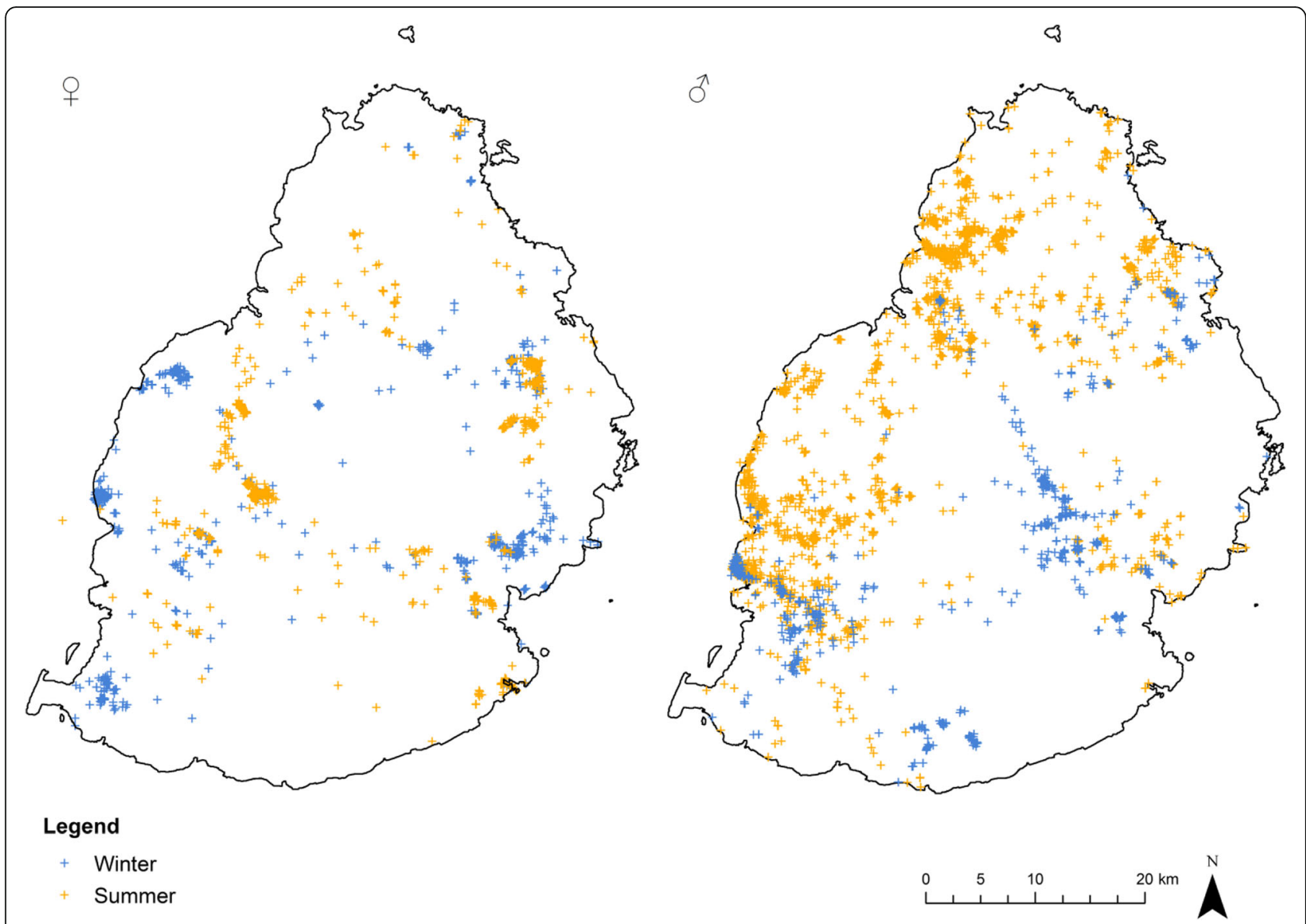

Fig. 3 Fixes recorded for females ( $N=6$ : left) and males $(N=6$ : right) during winter (April-September, (blue)) and summer (October-March, (yellow))

To define core foraging areas of the bats (Fig. 6), analysis of utilisation distribution discontinuities were used [23]. The analysis indicated that on average the bats used 90\% cluster cores as presumed foraging areas. The remaining $10 \%$ would have caused a disproportionate increase in areas utilised by the bats, since it included the paths they used to travel to and from the feeding sites.

Core foraging areas covered a mixture of habitats and varied among individual bats from 33 ha to 9421 ha for males with an average of 2222 ha ( \pm 3613 SD) and from 5392 ha to 1623 ha for females with an average of 1364 ha $( \pm 2061 \mathrm{SD})$. An independent samples T-test showed no significant difference between the sizes of male and female core foraging areas $(\mathrm{t}=0.505 ; \mathrm{df}=10 ; p=0.413)$. The overlap between the foraging areas of individuals was generally small with an average of $15.2 \%( \pm 21.0 \mathrm{SD})$ overlap.

\section{Discussion}

GSM tagging offers exciting new opportunities for studying the movement ecology of bats, especially for large flying fox species that roost in open areas such as in trees, where sunlight can recharge solar powered batteries. This recharging potential, coupled with access to GPS fixes via a mobile phone network, allows an understanding of the movement ecology of large bats over long time periods, providing insights into both shortand long-term use of space in ways that has hitherto not been possible. The return rate of fixes allowed nightly movements to be determined reliably, but was not sufficient to identify all foraging sites used in a night. Our study shows that Pteropus niger, despite living on a relatively small island, can cover large distances (the length of the island) sometimes in a single night, and that bats can move over much of the island in relatively short time periods. The bats can potentially respond rapidly to sudden changes in their environment by moving over large distances in short time periods. This nomadic movement pattern is consistent with the finding that $P$. niger show no obvious population structure on Mauritius [19].

Pteropus niger, along with other Pteropus species, is tree-roosting and thus dependent on vegetation cover [44]. Although 25\% of Mauritius is covered by forest fragments, only about $5 \%$ of the land cover consists of 

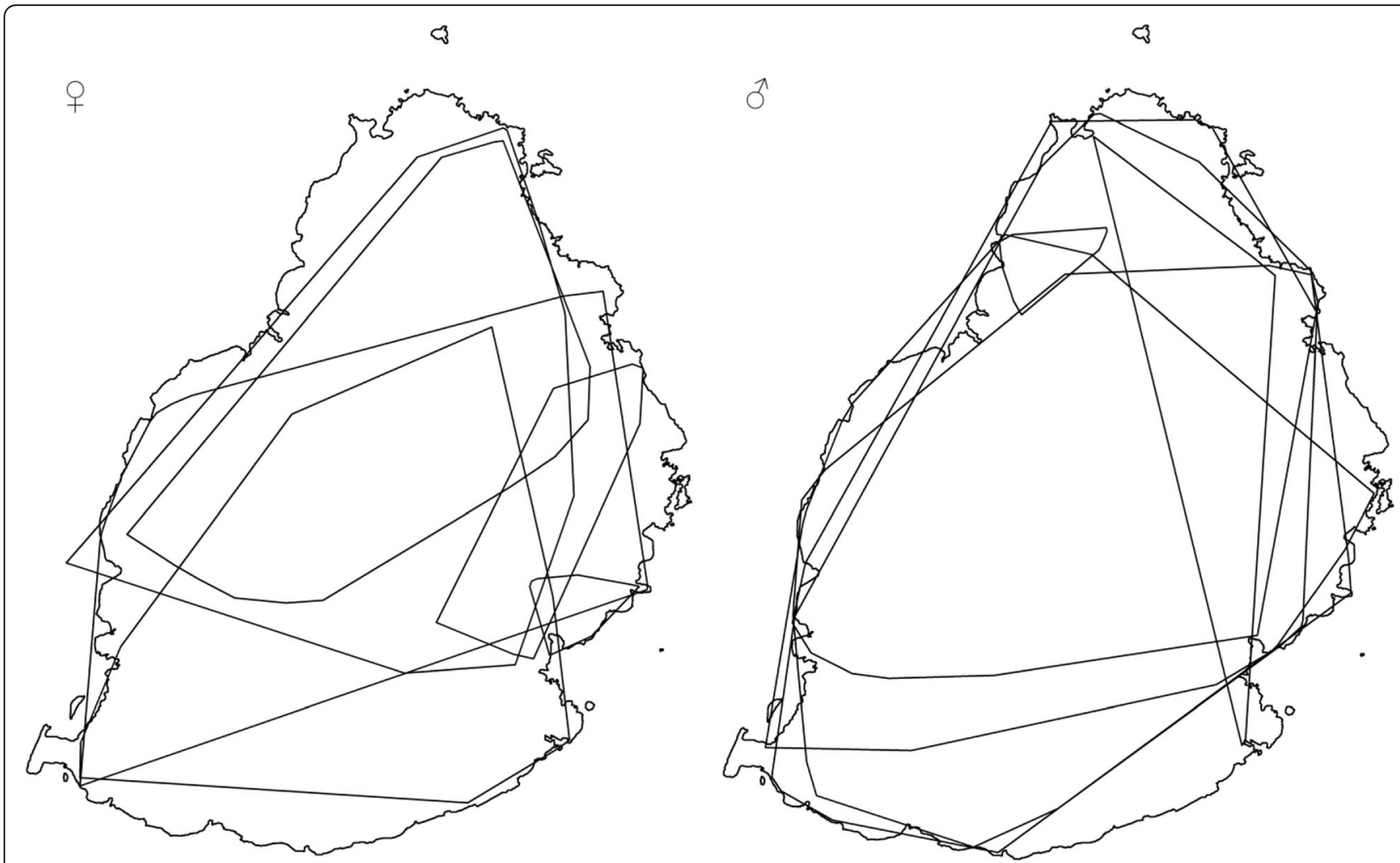

\section{Legend}

- Home range

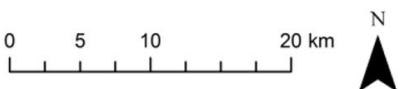

Fig. 4 Home ranges of females ( $N=6$ : left) and males ( $N=6$ : right) presented as minimum convex polygons

native forest, of which only a third has $>50 \%$ native canopy cover $[26,45]$. Given that $P$. niger uses forest extensively for roosting, and that it is a key disperser of the seeds of native tree species that form the forest canopy [20], conservation of the bats will promote the dispersal of canopy trees, whose growth will in turn provide suitable roosting sites for the bats. By choosing a suitable roosting site bats gain mating opportunities, reduced commuting costs to foraging sites, increased social interaction, and protection from adverse weather and predators [46-48]. In our study the bats used over 50 roosting sites distributed across the island, while recent NPCS reports highlight over 80 roosting sites (NPCS, pers. comm.).

Flying foxes are also highly mobile and their wing morphology allows them to track resources over large distances $(5-80 \mathrm{~km})$ and among scattered forest fragments [49-53]. In the present study the longest distance covered during one night by $P$. niger was over $92 \mathrm{~km}$ for a male and nearly $80 \mathrm{~km}$ for a female. Because Mauritius is a small island of only $1865 \mathrm{~km}^{2}$ with native forest cover of less than $100 \mathrm{~km}^{2}$, or $5 \%$ of the land area [17, 45, 54], bats are able to move across the island and between the forest fragments within one night. Therefore, Mauritius has no physical boundaries that impede the bats for tracking food resources or finding a mate, and the whole island is the potential home range of individual bats.

Movement between forested areas may be associated with finding a suitable roost or decreasing the distances travelled in search of food. Although $P$. niger roosts in public places such as the botanic garden in Pamplemousses and at Jardin de la Compagnie (a park in the capital city of Port Louis), the remnant forest patches provide much safer environments for roosting. Roosting in public places is a recent phenomenon (perhaps becoming prevalent only in the last decade) and could be the consequence of relatively high population levels (prior to culling), reduced levels of hunting prior to the cull, or to the loss of resources in remnant forest patches. Ultimately, the remaining forest fragments are crucial for the conservation of the species. Additionally, the scattered roosting sites shown in our study may act as stopovers, or be used seasonally to reduce commuting to feeding sites.

Adults of both sexes travelled longer distances in winter than in summer: this could be the consequence of reproductive demands on females in summer (although no females were obviously pregnant or had dependant young 


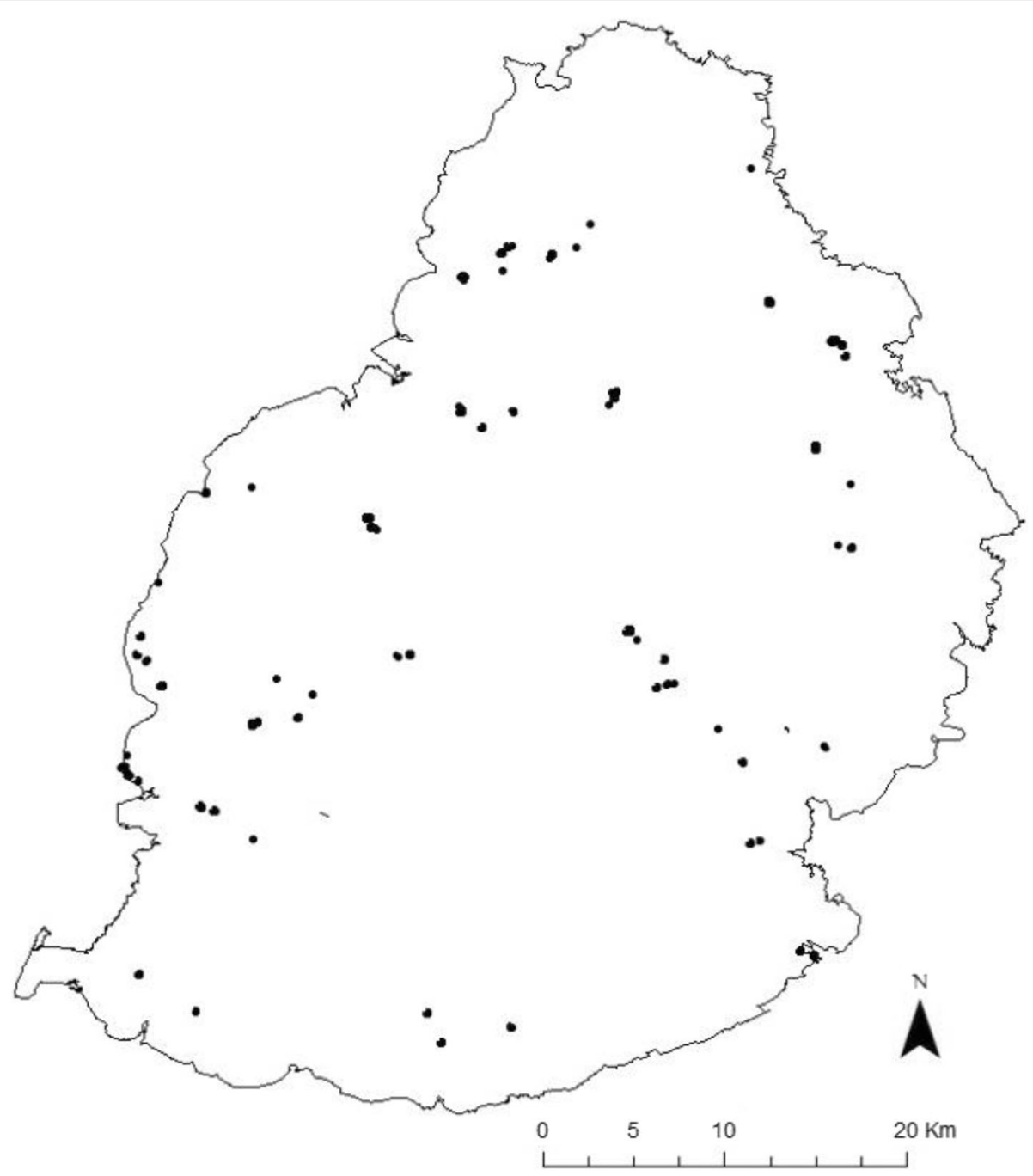

Fig. 5 Map of $P$. niger roosting sites used by all tracked bats $(N=12)$

at the time of capture, some may have given birth later). Between October and February, while females care for their pups, males may form 'bachelor' colonies (K. Ruhomaun, pers. com.). That would suggest that females form maternity colonies as for example in $P$. vampyrus natunae in Sarawak [55]. However, long-term monitoring of major roosting areas and a detailed analysis of roost switching behaviour are necessary to confirm such a pattern. Alternatively resources could be scarcer in winter, and bats may need to travel further to find them. We found no overall difference in the nightly distances covered by males and females. In Madagascar $P$. rufus females travelled significantly longer distances than males (average $28.1 \mathrm{~km}$ and $15.4 \mathrm{~km}$ respectively) [13]. Banack and Grant [55] found that juvenile male $P$. tonganus travel on long, so called 'exploratory flights' of up to $46.7 \mathrm{~km}$. We found that immature male $P$. niger travelled further per night in summer than in winter. This could be associated with dispersal (perhaps involving 'exploratory flights', as males are the dispersing sex in a wide range of mammal species) [56].

Other Pteropus species also show seasonal movement patterns. For example, Australian P. scapulatus makes seasonal movements in response to flowering and fruiting of their food plants [57]. Pteropus tonganus changes roosting sites in response to food availability [58]. In contrast, Bonin flying foxes $P$. pselaphon, exhibit seasonal changes in roosting patterns associated with the breeding cycle. They form colonial roosts in winter and dispersed roosts (more roosting sites with less individuals roosting together) in summer. In this case, roosting facilitates social interactions for mating and potentially also information exchange [48]. Our roosting observations suggest that Mauritius fruit bats form colonial roosts during the winter in the southern part of the 


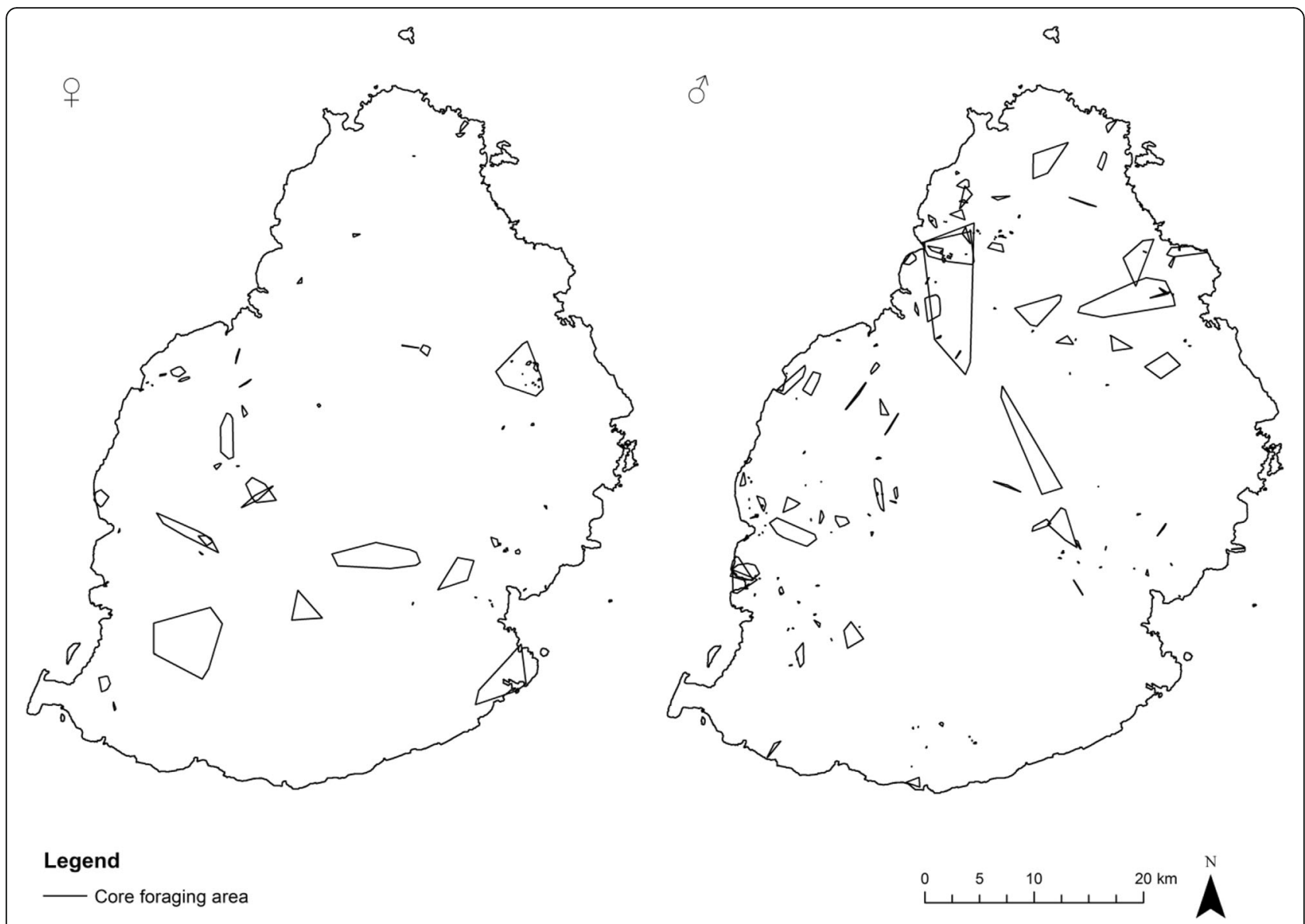

Fig. 6 Core foraging area of females ( $N=6$ : left) and males ( $N=6$ : right) presented as $90 \%$ cluster core polygons

island and roost more in the northern part during the summer. This pattern could be associated with the remaining forest cover. The Black River Gorges National Park in the south-west offers some of the last remaining primary forest fragments which may provide substantial quantities of food for the bats during winter. On the other hand, during the summer, the majority of both native and introduced plant species are fruiting across the island and the north of Mauritius is usually the first to bear native as well as commercial fruits such as mango or lychee due to its warmer climate [59]. That may explain the shift in distribution patterns.

Our results provide new information that has relevance for the conservation and management of $P$. niger. The recent culls have had a major impact on $P$. niger populations on Mauritius, and have been highly controversial [60]. None of the tagged bats disappeared during the 2015 organised cull, suggesting that the eight bats from which we lost signal were poached by local people. Hence the effects of local poaching may be substantial. For effective conservation of $P$. niger, broader conservation initiatives involving a number of stakeholders are needed [61, 62]. Increased use of netting to protect fruit will minimise conflict between fruit growers and bat conservation [28]. Culling may force bats into new areas where they were previously not eating commercial fruit [63]. Indeed, the recent culls have failed to increase commercial profits at fruit farms [64]. Our data provide context by showing that the bats cover very large distances and any effects of culling will not be localised and may have little impact over broad spatial scales.

\section{Conclusion}

Pteropus niger is similar to other Pteropus species and can travel long distances during the night in search of food and for social and mating interactions. The home range of the species is the whole island of Mauritius and bats frequently move between the roosts and remnant forest fragments that are important for bat conservation. The vagility of the species explains its panmictic genetic structure. At present the extent of the cull is of major concern given that over $95 \%$ of native forest has been lost since $1638[65,66]$ and remaining native forest patches are being degraded by invasive plant species that 
may affect the availability of native fruit species [65]: the Mauritian flying fox plays a vital role in the dispersal of native and endemic plant species [20]], and probably in enhancing seed germination and potentially forest regeneration over large spatial scales as occurs with another endemic flying fox species (Pteropus rufus) in nearby Madagascar [14]. The role of $P$. niger as a seed disperser is especially important at present, as it is the largest extant seed disperser on Mauritius following the extirpation of megafauna such as giant tortoises [67]. The cull is currently based on a lack of scientific evidence [68]. Although $P$. niger can move large distances in short time periods and can therefore respond rapidly to threats and environmental change over small spatial scales, it is effectively 'trapped' on a small island where it is difficult to escape the effects of mass culling. Culling is unlikely to have localised benefits for reducing damage at orchards given the extensive movements of the bats.

\section{Additional file}

Additional file 1: Table S1. Description of the top five most parsimonious GLMMs built to test whether nightly movement of Pteropus niger differs between sex (male vs. female), age (sexually mature vs. immature), and season (summer vs. winter). Models are ranked in ascending order of AICC. The number of parameters $(K)$, AlCc weight $(W t)$, and cumulative weight (Cum. Wt) are given for each model. The model that includes the three-way interactions was considered as the best one. Table S2. Results of the post hoc contrast tests applied to the most parsimonious GLMM that included the three-way interactions between sex (male vs. female), age (sexually mature vs. immature), and season (summer vs. winter) for explaining nightly movement of Pteropus niger. Estimate with associated standard error (SE) as well as $Z$ ratio and adjusted $P$-value are given for each comparison. (DOCX $18 \mathrm{~kb}$ )

\section{Abbreviations \\ F: Female; GPS: Global Positioning System; GSM: Global System for Mobile Communications; IUCN: International Union for the Conservation of Nature: M: Male; NPCS: National Parks and Conservation Services; SI: Sexually immature; SM: Sexually mature}

\section{Acknowledgements}

The paper is dedicated to the memory of Christiane Howey, whose husband made the study possible. The main sponsor of the study was The Rufford Small Grants Foundation and IUCN's Save Our Species Rapid Action Grant. The GPS tags were kindly donated by Microwave Telemetry Inc. Emtel Ltd. donated SIM cards for the GPS tags and provided free technical support related to formatting and modification of cards. We thank all the people of Mauritius involved in the study and the data collection. We thank Mrs. Deborah de Chazal (Executive Director) at the Mauritian Wildlife Foundation for her help with the project. The study was conducted in collaboration with the National Park and Conservation Services of Mauritius.

\section{Funding}

We thank The Rufford Small Grants Foundation and IUCN's Save Our Species Rapid Action Grant for support.

\section{Availability of data and materials}

The datasets used and/or analysed during the current study are available from the corresponding author on reasonable request.

\section{Authors' contributions}

$\mathrm{RO}$ collected and analysed the data; LA was directly involved in data collection; VT and $\mathrm{CJ}$ provided logistical support; PH donated the tags to the study and helped with their technical aspects; JSPF contributed to data analysis. PR and GJ made substantial contributions to conception and design and interpretation of the data, provided academic support and guidance as well as help with manuscript writing and reviews; all the authors reviewed and approved the manuscript.

Ethics approval and consent to participate

The study was approved by The Ministry of Agro-Industry and Food Security as well as National Parks and Conservation Services, Mauritius (REF. 2013/M59/1341).

\section{Consent for publication}

Not Applicable

\section{Competing interests}

The authors declare that they have no competing interests. PH of Microwave Telemetry is included as a co-author in the study as he donated the tags.

\section{Publisher's Note}

Springer Nature remains neutral with regard to jurisdictional claims in published maps and institutional affiliations.

\section{Author details}

${ }^{1}$ School of Biological Sciences, Life Sciences Building, University of Bristol, 24 Tyndall Avenue, Bristol BS8 1TQ, UK. ${ }^{2}$ Department of Zoology, The George S. Wise Faculty of Life Science Tel Aviv University, P.O. Box 39040, Tel Aviv, Israel. ${ }^{3}$ Ecosystem Restoration Alliance Indian Ocean, No. 7 Site and Services, Circonstance, St. Pierre, Mauritius. ${ }^{4}$ Durrell Wildlife Conservation Trust, Les Augrès Manor, Trinity, Channel Islands JE3 5BP, Jersey. ${ }^{5}$ Mauritian Wildlife Foundation, Grannum Road, Vacoas, Mauritius. ${ }^{6}$ Microwave Telemetry, Inc, 8835 Columbia, 100 Parkway, Suites K \& L, Columbia, MD 21045, USA. ${ }^{7}$ Centre for Ecology and Conservation, School of Biosciences, University of Exeter, Penryn Campus, Penryn TR10 9FE, UK.

Received: 20 December 2018 Accepted: 12 March 2019

Published online: 15 April 2019

\section{References}

1. Nathan R. An emerging movement ecology paradigm. Proc Natl Acad Sci. 2008:105:19050-1.

2. Fahrig L. Non-optimal animal movement in human-altered landscapes. Funct Ecol. 2007;21:1003-15.

3. McIntyre NE, Wiens JA. Interactions between landscape structure and animal behavior: the roles of heterogeneously distributed resources and food deprivation on movement patterns. Landsc Ecol. 1999;14:437-47.

4. Schweiger O, Heikkinen RK, Harpke A, Hickler T, Klotz S, Kudrna O, et al. Increasing range mismatching of interacting species under global change is related to their ecological characteristics. Glob Ecol Biogeogr. 2012;21:88-99.

5. Avgar T, Mosser A, Brown GS, Fryxell JM. Environmental and individual drivers of animal movement patterns across a wide geographical gradient. J Anim Ecol. 2013:82:96-106.

6. Moussy C, Hosken DJ, Mathews F, Smith GC, Aegerter JN, Bearhop S. Migration and dispersal patterns of bats and their influence on genetic structure. Mammal Rev. 2013;43:183-95.

7. Clobert J, Baguette M, Benton TG, Bullock JM. Dispersal ecology and evolution. Oxford: Oxford University Press; 2012.

8. Jeltsch F, Bonte D, Pe'er G, Reineking B, Leimgruber P, Balkenhol N, et al. Integrating movement ecology with biodiversity research - exploring new avenues to address spatiotemporal biodiversity dynamics. Mov. Ecol. 2013;1:1-13.

9. Krauel JJ, McCracken GF. Recent advances in bat migration research. In: Adams R, Pedersen S, editors. Bat evolution, ecology, and conservation. New York: Springer; 2013. p. 293-313

10. Dodge S, Bohrer G, Weinzierl R, Davidson SC, Kays R, Douglas D, et al. The environmental-DATA automated track annotation (Env-DATA) system: linking animal tracks with environmental data. Mov Ecol. 2013;1:3.

11. Mueller T, Lenz J, Caprano T, Fiedler W, Böhning-Gaese K. Large frugivorous birds facilitate functional connectivity of fragmented landscapes. J Appl Ecol. 2014;51:684-92

12. Neuschulz EL, Mueller T, Schieuning M, Böhning-Gaese K. Pollination and seed dispersal are the most threatened processes of plant regeneration. Sci Rep. 2016:6:29839.

13. Oleksy R, Racey PA, Jones G. High-resolution GPS tracking reveals habitat selection and the potential for long-distance seed dispersal by Madagascan flying foxes Pteropus rufus. Glob. Ecol. Conserv. 2015;3:678-92. 
14. Oleksy R, Giuggioli L, McKetterick TJ, Racey PA, Jones G. Flying foxes create extensive seed shadows and enhance germination success of pioneer plant species in deforested Madagascan landscapes. PLoS ONE. 2017;12:e0184023.

15. Abedi-Lartey M, Dechmann DKN, Wikelski M, Scharf AK, Fahr J. Longdistance seed dispersal by straw-coloured fruit bats varies by season and landscape. Glob Ecol Conserv. 2016;7:12-24.

16. Cheke AS, Dahl JF. The status of bats on western Indian Ocean islands, with special reference to Pteropus. Mammalia. 1981;45:205-38.

17. Cheke AS, Hume JP. Lost land of the dodo: an ecological history of Mauritius, Réunion and Rodrigues. London: T \& AD Poyser; 2008.

18. Chan LM, Goodman SM, Nowak MD, Weisrock DW, Yoder AD. Increased population sampling confirms low genetic divergence among Pteropus (Chiroptera: Pteropodidae) fruit bats of Madagascar and other western Indian Ocean islands. PLoS Curr. 2011;1. https://doi.org/10.1371/currents. RRN1226.

19. Larsen PA, Hayes CE, Wilkins MA, Gomard Y, Sookhareea R, Yoder AD, et al. Population genetics of the Mauritian flying fox, Pteropus niger. Acta Chiropterologica. 2014;16:293-300.

20. Florens FBV, Baider C, Marday V, Martin GMN, Zmanay Z, Oleksy R, et al. Disproportionately large ecological role of a recently mass-culled flying fox in native forests of an oceanic island. J. Nature Conserv. 2017:40:85-93.

21. Myers N, Mittermeier RA, Mittermeier CG, da Fonseca GAB, Kent J. Biodiversity hotspots for conservation priorities. Nature. 2000;403:853-8.

22. Hutson AM, Mickleburgh SP, Racey PA. Old World fruit bats: an action plan for their conservation. Gland: International Union for the Conservation of Nature; 1992.

23. Nyhagen DF, Turnbull SD, Olesen JM, Jones CG. An investigation into the role of the Mauritian flying fox, Pteropus niger, in forest regeneration. Biol Conserv. 2005:122:491-7.

24. Pierson ED, Elmqvist T, Rainey WE, Cox PA. Effects of tropical cyclonic storms on flying fox populations on the South Pacific Islands of Samoa. Conserv Biol. 1996;10:438-51.

25. Grant GS, Craig P, Trail P. Cyclone-induced shift in foraging behavior in flying foxes in American Samoa. Biotropica. 1997;29:224-8.

26. Kingston T, Florens V, Oleksy R, Ruhomaun K, Tatayah V. Pteropus niger. The IUCN Red List of Threatened Species. 2018; e.T18743A8647552. Downloaded on 10 August 2018.

27. Vincenot CE, Florens FBV, Kingston T. Can we protect island flying foxes? Science. 2017;355:1368-70.

28. Oleksy R, Ayady CL, Tatayah V, Jones C, Froidevaux JSP, Racey PA, Jones G. The impact of the Mauritian flying fox (Pteropus niger) on commercial fruit farms and the efficacy of mitigation. Oryx. 2018; https://doi.org/10.1017/ S0030605318001138.

29. Bridge ES, Thorup K, Bowlin MS, Chilson PB, Diehl RH, Fléron RW, et al. Technology on the move: recent and forthcoming innovations for tracking migratory birds. Bioscience. 2011;61:689-98.

30. Racey PA. Reproductive assessment of bats. In: Kunz TH, Parsons S, editors. Ecological and behavioral methods for the study of bats. Baltimore: The Johns Hopkins University Press; 2009. p. 249-64.

31. Heideman PD. The timing of reproduction in the fruit bat Haplonycteris fischeri (Pteropodidae): geographic variation and delayed development. J. Zool., Lond. 1988;215:577-95

32. Van Winkle W. Comparison of several probabilistic home-range models. J Wildl Manag. 1975;39:118.

33. Kenward RE. Wildlife radio-tagging. Equipment, field techniques and data analysis. London: Academic Press; 1987.

34. Kenward RE. A manual for wildlife radio tagging. San Diego: Academic Press; 2001.

35. Davidson-Watts I, Walls S, Jones G. Differential habitat selection by Pipistrellus pipistrellus and Pipistrellus pygmaeus identifies distinct conservation needs for cryptic species of echolocating bats. Biol Conserv. 2006;133:118-27.

36. Zeale MRK, Jones G. Home range use and habitat selection by barbastelle bats (Barbastella barbastellus): impications for conservation. J Mammal. 2012; 93:1110-8.

37. South $A B$, Kenward RE. Ranges 7, software for the analysis of tracking and location data. Wareham: Anatrack Ltd.; 2006.

38. R Development Core team. R: a language and environment for statistical computing. Vienna: R Foundation for Statistical Computing; 2017.

39. Bates D, Machler M, Bolker BM, Walker SC. Fitting linear mixed-effects models using Ime4. J Stat Softw. 2015;67:1-48.
40. Hartig F. DHARMa: residual diagnostics for hierarchical (multi-level/mixed) regression models. R package version 0.1.5. Available at: https://CRAN.Rproject.org/package=DHARMa (accessed 8 Jan. 2018). 2017.

41. Bartoń K. MuMln: Multi-Model Inference. R package version 1.15.6. 2016.

42. Burnham KP, Anderson DR. Model selection and multimodel inference: a practical information - theoretic approach. New York: Springer; 2002.

43. Lenth RV. Least-squares means: the R package Ismeans. J Stat Softw. 2016;69:1-33.

44. Mackinnon JL, Hawkins CE, Racey PA. Pteropodidae, fruit bats, Fanihy Angavo. In: Goodman SM, Benstead JP, editors. The natural history of Madagascar. Chicago: University of Chicago Press; 2003. p. 1299-303.

45. Hammond DS, Gond V, Baider C, Florens FBV, Persand S, Laurance SGW. Threats to environmentally sensitive areas from peri-urban expansion in Mauritius. Environ Conserv. 2015;42:256-67.

46. Gumal MT. Diurnal home range and roosting trees of a maternity colony of Pteropus vampyrus natunae (Chiroptera: Pteropodidae) in Sedilu. Sarawak Trop Ecol. 2004;20:247-58

47. Kunz TH, Lumsden LF. Ecology of cavity and foliage roosting bats. In: Kunz $\mathrm{TH}$, Fenton MB, editors. Bat ecology. Chicago: University of Chicago Press; 2003. p. 3-89.

48. Sugita N, Inaba M, Ueda K. Roosting pattern and reproductive cycle of Bonin flying foxes (Pteropus pselaphon). J Mammal. 2009;90:195-202.

49. Thomson SC, Brooke AP, Speakman JR. Soaring behaviour in the Samoan flying fox (Pteropus samoensis). J Zool. 2006;256:55-62.

50. Jenkins RKB, Andriafidison D, Razafimanahaka HJ, Rabearivelo A, Razafindrakoto N, Ratsimandresy Z, et al. Not rare, but threatened: the endemic Madagascar flying fox Pteropus rufus in a fragmented landscape. Oryx. 2007:41:263-71.

51. McConkey KR, Drake DR. Indirect evidence that flying foxes track food resources among islands in a Pacific archipelago. Biotropica. 2007;39:436-40.

52. Richter HV, Cumming GS. First application of satellite telemetry to track African straw-coloured fruit bat migration. J Zool. 2008;275:172-6.

53. Epstein JH, Olival KJ, Pulliam JRC, Smith C, Westrum J, Hughes T, et al. Pteropus vampyrus, a hunted migratory species with a multinational homerange and a need for regional management. J Appl Ecol. 2009;46:991-1002.

54. Cheke A. The legacy of the dodo - conservation in Mauritius. Oryx. 1987;21: 29-36.

55. Banack SA, Grant GS. Reproduction and behaviour of the Samoan flying fox, Pteropus samoensis (Chiroptera, Pteropodidae). Mammalia. 2003:67:419-37.

56. Mabry KE, Shelley EL, Davis KE, Blumstein DT, Van Vuren DH. Social mating system and sex-biased dispersal in mammals and birds: a phylogenetic analysis. PLoS ONE. 2013;8(3):e57980.

57. Webb NJ, Tidemann CR. Mobility of Australian flying-foxes, Pteropus spp (Megachiroptera): evidence from genetic variation. Proc. R. Soc. London Ser. B-Biological Sci. 1996;263:497-502.

58. Banack SA, Grant GS. Spatial and temporal movement patterns of the flying fox, Pteropus tonganus, in American Samoa. J Wildl Manag. 2002;66:1154-63.

59. Safford RJ. Mauritius. In: Fishpool LDC, Evans MI, editors. Important Bird Areas in Africa and Associated Islands: Priority Sites for Conservation Newbury and Cambridge: Pisces Publications and BirdLife International; 2001. p. 583-596.

60. Florens FBV. Biodiversity law: Mauritius culls threatened fruit bats. Nature. 2016;530:33.

61. Florens FBV, Vincenot CE. Broader conservation strategies needed. Science. 2018;362:409.

62. Anthony BP, Tatayah V, Chazal DD. Taking the first steps: initial mapping of the human-wildlife interaction of the Mauritius fruit bat Pteropus niger by conservation organizations. J threat taxa. 2018;8:12073-81.

63. Olival KJ. To cull, or not to cull, bat is the question. EcoHealth. 2016;13:6-8

64. Florens FBV, Baider C. Mass-culling of a threatened island flying fox species failed to increase fruit growers' profits and revealed gaps to be addressed for effective conservation. J Nature Conserv. 2019:47:58-64.

65. Florens FBV. Conservation in Mauritius and Rodrigues: challenges and achievements from two ecologically devastated oceanic islands. In: Raven PH, Sodhi NS, Gibson L, editors. Conservation biology: voices from the tropics. Oxford: John Wiley \& Sons Ltd.; 2013.

66. Norder SJ, Seijmonsbergen AC, Rughooputh SD, van Loon EE, Tatayah V Kamminga AT, Rijsdijk KF. Assessing temporal couplings in social-ecological island systems: historical deforestation and soil loss on Mauritius (Indian Ocean). Ecology and Society. 2017;22:29.

67. Hansen DM, Galetti M. The forgotten megafauna. Science. 2009:324:42-3.

68. Florens FBV. Flying foxes face cull despite evidence. Science. 2015;350:1325. 